\title{
Neonatal Atypical Hemolytic Uremic Syndrome in the Eculizumab Era
}

\author{
Sara Madureira Gomes, MD ${ }^{1}$ Rita Pissarra Teixeira, MD ${ }^{1}$ Gustavo Rocha, MD ${ }^{2}$ Paulo Soares, MD $^{2}$ \\ Hercilia Guimaraes, $\mathrm{PhD}^{3}$ Paulo Santos, $\mathrm{MD}^{4}$ Joana Jardim, $\mathrm{MD}^{5}$ João Luís Barreira, $\mathrm{MD}^{5}$ \\ Helena Pinto, $\mathrm{MD}^{5}$
}

${ }^{1}$ Department of Pediatrics, Centro Hospitalar Universitário de São João, Porto, Portugal

2 Department of Neonatology, Centro Hospitalar Universitário de São João, Porto, Portugal

3 Department of Pediatrics, Faculty of Medicine, University of Porto, Porto, Portugal

${ }^{4}$ Department of Pediatric Cardiology, Centro Hospitalar Universitário de São João, Porto, Portugal

5 Pediatric Nephrology Unit, Department of Pediatrics, Centro

Hospitalar Universitário de São João, Porto, Portugal

\begin{abstract}
Address for correspondence Sara Madureira Gomes, MD, Serviço de Pediatria, Centro Hospitalar Universitário de São João, Alameda Prof. Hernâni Monteiro, 4200-319 Porto, Portugal

(e-mail: sara.gomes1@hotmail.com).
\end{abstract}

AJP Rep 2021;11:e95-e98.

\begin{abstract}
Keywords

- atypical hemolytic uremic syndrome

- thrombotic microangiopathy

- neonate

- eculizumab

- perinatal asphyxia

The atypical hemolytic uremic syndrome (aHUS) in the newborn is a rare disease, with high morbidity. Eculizumab, considered a first-line drug in older children, is not approved in neonates and in children weighing less than $5 \mathrm{~kg}$. We present a 5-day-old female newborn, born at 36 weeks' twin gestation, by emergency cesarean section due to cord prolapse, with birth weight of $2,035 \mathrm{~g}$ and Apgar score of $7 / 7 / 7$, who develops microangiopathic hemolytic anemia, thrombocytopenia, and progressive acute renal failure. In day 5 , after diagnosis of aHUS, a daily infusion of fresh frozen plasma begins, with improvement of thrombocytopenia and very slight improvement in renal function. The etiologic study (congenital infection, Shiga toxin, ADAMTS13 activity, directed metabolic study) was normal. C3c was slightly decreased. On day 16 for maintenance of anemia and severe renal failure, she started $300 \mathrm{mg} /$ dose eculizumab. Anemia resolves in 10 weeks and creatinine has normal values after 13 weeks of treatment. The genetic study was normal. In this case, eculizumab is effective in controlling microangiopathy and in the recovery of renal function. Diagnosis of neonatal aHUS can be challenging because of phenotypic heterogeneity and potential overlap with other manifestations that may confound it, such as perinatal asphyxia or sepsis/disseminated intravascular coagulation.
\end{abstract}

Hemolytic uremic syndrome (HUS) is a thrombotic microangiopathy, characterized by the triad of hemolytic anemia, thrombocytopenia, and acute kidney injury. ${ }^{1-3}$

In contrast to typical HUS, secondary to Shiga toxins, atypical HUS (aHUS) results from abnormalities of the alter- native complement pathway or rare metabolic diseases. aHUS is a severe and rare disease, accounting for 5 to $10 \%$ of pediatric HUS, with an even rarer presentation in the neonatal period. ${ }^{1,4}$ Its prognosis is poor, with a significant risk of progression to chronic kidney disease, recurrences, and fatal cases. 1,5,6 received

February 15, 2021

accepted

March 25, 2021
DOI https://doi.org/ $10.1055 / \mathrm{s}-0041-1731057$. ISSN 2157-6998.

\footnotetext{
(C) 2021. The Author(s).

This is an open access article published by Thieme under the terms of the Creative Commons Attribution-NonDerivative-NonCommercial-License, permitting copying and reproduction so long as the original work is given appropriate credit. Contents may not be used for commercial purposes, or adapted, remixed, transformed or built upon. (https://creativecommons.org/ licenses/by-nc-nd/4.0/) Thieme Medical Publishers, Inc., 333 Seventh Avenue, 18th Floor, New York, NY 10001, USA
} 
Currently, eculizumab is considered the first-line treatment of aHUS in older children. ${ }^{2,7}$ It is a recombinant humanized monoclonal antibody that specifically binds to complement C5 protein, with great affinity, blocking the complement cascade and stopping the endothelial injury. Nevertheless, there are very few cases described in the literature about eculizumab use in newborns and children weighing less than $5 \mathrm{~kg}^{4,8-15}$

\section{Case Presentation}

We present a case of a 5-day-old female newborn, born at 36 weeks' monozygotic (monochorionic diamniotic) twin gestation, to nonconsanguineous parents. Routine prenatal evaluation was unremarkable. She was born by emergency cesarean section due to cord prolapse and pelvic presentation. Her birth weight was 2,035 g and Apgar score was 7/7/7 (at 1,5, and 10 minutes, respectively). In the first hour of life, she appeared pale, hyporeactive, and grunting. Venous blood gas analysis demonstrated a metabolic acidosis $(\mathrm{pH} 7.14$, $\left.\mathrm{HCO}_{3} 15 \mathrm{mmol} / \mathrm{L}\right)$ with an elevated lactate $(12 \mathrm{mmol} / \mathrm{L})$. Hypotension was established and fluid resuscitation was done with $0.9 \%$ saline solution in a bolus of $20 \mathrm{~mL} / \mathrm{kg}$. Subsequently, the metabolic acidosis was improved $(\mathrm{pH}$ $7.30, \mathrm{HCO}_{3} 20 \mathrm{mmol} / \mathrm{L}$, lactate $4 \mathrm{mmol} / \mathrm{L}$ ) but the hypotension persisted, with an apparent differential between upper and lower limbs, and the appearance of a systolic murmur. Blood analysis showed hemoglobin of $10.5 \mathrm{~g} / \mathrm{dL}$, white blood cells of $24 \times 10^{9} / \mu \mathrm{L}$, platelets (PLTs) of $201 \times 109 / \mu \mathrm{L}$, and negative C-reactive protein (CRP). Then she was referred to our tertiary hospital for evaluation by pediatric cardiology, due to suspicion of aortic coarctation, which was not confirmed.

On admission, still in day 1 (D1), she presented pale, hydrated, on spontaneous ventilation without signs of respiratory distress and hemodynamically stable. In the analytical reassessment, she presented a worsened anemia (hemoglobin $8.8 \mathrm{~g} / \mathrm{dL})$, thrombocytopenia $\left(33 \times 10^{9} / \mu \mathrm{L}\right)$, elevated liver enzymes (aspartate aminotransferase $327 \mathrm{U} / \mathrm{L}$ and alanine aminotransferase $81 \mathrm{U} / \mathrm{L}$ ), acute kidney injury (urea 63 $\mathrm{mg} / \mathrm{dL}$; creatinine $1.61 \mathrm{mg} / \mathrm{dL}$ ), and a negative CRP. Urine and blood cultures were collected and she started ampicillin and gentamicin in the suspicion of neonatal sepsis. Red blood cell (RBC) and PLT concentrate transfusions were also performed.

In the next 3 days, she maintained anemia and thrombocytopenia, without the need for further transfusions, hepatic dysfunction subsided but acute kidney injury worsened considerably and lactate dehydrogenase (LDH) values were very much elevated. Subsequently, pediatric nephrology collaboration was requested.

At that moment, she had normal blood pressure, normal diuresis $(2.5 \mathrm{~mL} / \mathrm{kg} / \mathrm{h})$ and no peripheral edemas. Physical examination was unremarkable with the exception of pallor. Cultures were negative. Blood analysis confirmed a microangiopathic hemolytic anemia (hemoglobin $10.1 \mathrm{~g} / \mathrm{dL}$, increased $\mathrm{LDH}$ of 3,387 $\mathrm{U} / \mathrm{L}$, undetectable serum haptoglobin, negative direct Coombs' test and presence of 2 to 4 schizocytes/high power field in the peripheral blood smear), thrombocytopenia $\left(112 \times 10^{9} / \mu \mathrm{L}\right)$, hypoproteinemia and hypoalbuminemia ( 42 and $24 \mathrm{~g} / \mathrm{L}$, respectively), elevated serum urea and creatinine (196 and $4.59 \mathrm{mg} / \mathrm{dL}$, respectively), hyperphosphatemia, and hyponatremia. Coagulation tests were normal. Hematuria $(230 \mathrm{RBC} / \mu \mathrm{L})$ and proteinuria (urine protein to creatinine ratio of $33 \mathrm{mg} / \mathrm{mg}$ ) were also detected. Abdominal ultrasound and transfontanellar encephalic ultrasound were unremarkable. Based on the clinical presentation and the analytical results, an aHUS/thrombotic thrombocytopenic purpura was diagnosed.

The complementary etiological study included complement evaluation which revealed low levels of $\mathrm{C} 3 \mathrm{c}(73 \mathrm{mg} / \mathrm{dL}$; normal range $83-177 \mathrm{mg} / \mathrm{dL}$ ), negative Shiga toxin test, normal ADAMTS13 activity (69\%), and normal metabolic screening (including homocysteine, plasma amino acid levels, and urine organic acids). The genetic study excluded mutations in the complement genes CFH, CFI, CD46 (membrane cofactor protein [MCP]), C3, CFB, THBD, CFHR1, CFHR3, CFHR4, CFHR5, and DGKE. There were also no major deletions/duplications in the genes CFH, CFI, CD46 (MCP) nor the deletion CFHR3-1 in homozygosity.

On day 5 (D5), after presumptive diagnosis of aHUS, she was started on fresh frozen plasma infusion $(10 \mathrm{~mL} / \mathrm{kg}$, od). On day 15 (D15), eculizumab was started, $300 \mathrm{mg} / \mathrm{dose}$, repeated in the following week and then every 3 weeks.

Between D5 and D15, anemia was worsened $(7.5 \mathrm{~g} / \mathrm{dL})$, thrombocytopenia was resolved, and acute kidney injury was slightly improved (creatinine $2.77 \mathrm{mg} / \mathrm{dL}$ ). After starting eculizumab, LDH normalization was achieved after 7 days, hemoglobin normalization was achieved after 70 days, a decrease of plasma creatinine $\geq 25 \%$ was achieved after 7 days, and the improvement from baseline to week 27 in estimated glomerular filtration rate was $61 \mathrm{~mL} / \mathrm{min} / 1.73 \mathrm{~m}^{2}$ with normal creatinine levels achieved after 13 weeks of treatment ( - Fig. 1). Proteinuria and hematuria completely disappeared after 90 days of treatment. She needed RBC transfusions on days 18 and 40.

At the same time as eculizumab, she was started on prophylactic antibiotic with ampicillin while hospitalized and, after discharge (day 41), oral amoxicillin. Serogroup B meningococcal vaccine was performed at day 20 (D20) (dose 0), 2 months (dose 1), 4 months (dose 2), 6 months (dose 3), and a booster dose at 13 months and serogroups A, C, Y, and W135 meningococcal vaccine was performed at D20 (dose 0), 2 months (dose 1), 4 months (dose 2), and a booster dose at 13 months. Administration of both vaccines on D20 needed authorization by the ethics committee and the medical board due to its off-label administration. There were no undesirable effects.

Family close contacts also performed antimeningococcal vaccines: her brother and twin sister did the same vaccines which were adapted to age schemes. Parents and maternal grandparents did only serogroups A, C, Y, and W135 meningococcal vaccine.

At 14 months of age, while doing eculizumab and despite always being asymptomatic, her renal function was transitorily worsened (urea $65 \mathrm{mg} / \mathrm{dL}$, creatinine $0.45 \mathrm{mg} / \mathrm{dL}$, C cystatin 1.8 [normal range $0.53-0.95$ ], glomerular filtration 


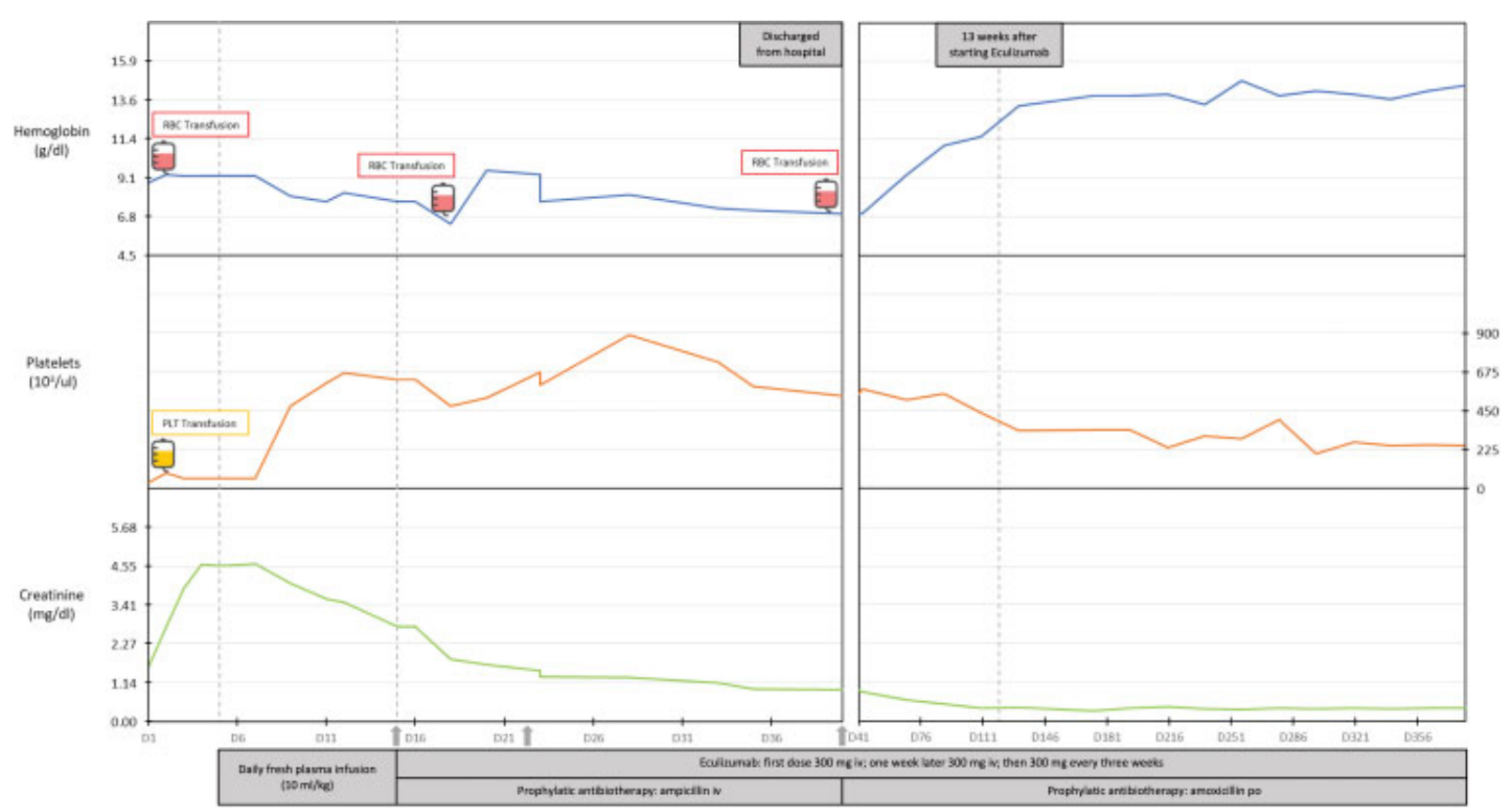

Fig. 1 Evolution of hemoglobin, platelets, and creatinine levels before and after eculizumab treatment. RBC, red blood cells; PLT, platelets; iv, intravenous; po, per os.

rate [Schwartz formula] $69 \mathrm{~mL} / \mathrm{min} / 1.73 \mathrm{~m}^{2}$ ). Hematological parameters, haptoglobin, LDH, viral serologies, complement, and urine remained normal. This episode occurred concomitantly with a probable viral infection of both siblings. Our patient recovered to baseline renal function in 3 weeks.

At the present time, at 20 months of age, she maintains treatment with eculizumab, she has never had any febrile episode, and complete blood counts and renal function are normal. She is in the 15 th to 50 th percentiles for both weight and height and she has an adequate psychomotor development.

\section{Discussion}

We report a newborn with aHUS for whom eculizumab treatment was effective in the recovery of hematological (namely anemia) and renal function parameters.

The 10-day delay in administration after diagnosis was imposed by the absence of recommendations currently available for eculizumab dosing in children younger than 1 month or weighing less than $5 \mathrm{~kg}$. That fact led to the requirement of prior authorization from the ethics committee and the medical board of our hospital. In the meantime, as plasmapheresis was considered unsuitable for a $2.0-\mathrm{kg}$ neonate, fresh frozen plasma infusion was started and had a partial beneficial effect, with resolution of thrombocytopenia and slight improvement of the severe acute kidney failure.

An important remark is the fact that eculizumab dose of $300 \mathrm{mg}$, in a subsequent maintenance schedule every 3 weeks, proved to be effective and safe, keeping this child under clinical control and without complications.

Prevention of Neisseria meningitidis infection is mandatory in patients receiving eculizumab due to complement blockage. $^{2,7}$ As previously described, neither vaccines nor prophylaxis guarantees complete protection, as there have been reported cases of invasive meningococcal disease in patients treated with eculizumab and vaccinated. ${ }^{7,16,17}$ In our patient, prevention took on several aspects: vaccination, vaccination of close contacts, and antibiotic prophylaxis, which the patient still maintains. In respect to vaccination, this patient did a dose 0 of serogroup $B$ meningococcal vaccine and serogroups $A, C, Y$, and W135 meningococcal vaccine at 20th day of life, well tolerated and without side effects. It was also the first time we proposed vaccination of close contacts and, in our view, this was justified by the child's early age, to optimize prevention.

Also noteworthy is the fact that our patient presented signs and symptoms of perinatal asphyxia (metabolic acidosis with $\mathrm{pH}<7.2$, Apgar score persistently of 7 in the first 10 minutes of life, hypotension, hypoactivity, elevated liver enzymes), which could have been triggered by the cord prolapse. Nevertheless, given the presence of anemia, thrombocytopenia, the degree of acute kidney injury at D1, and the subsequent clinical evolution, we postulate that aHUS was already being established. Eventually, it may have contributed to perinatal asphyxia (mainly due to anemia) and afterward, being worsened or accelerated by its presence. There are a few cases described in the literature of the association between perinatal asphyxia and aHUS. ${ }^{12,13,18}$ This suggests the hypothesis that endothelial injury by ischemia, hypoxia, and acidosis may lead to a vicious cycle that perpetuates the microangiopathic cascade.

The decrease of $\mathrm{C} 3 \mathrm{c}$, although slight, pointed to the existence of a complement mutation. However, as described in 30 to $40 \%$ of contemporary aHUS cases, ${ }^{1,5}$ we could not detect a complement regulatory factor mutation in the 
genes studied. Genetic study is still in process. We hope in some years, genetics could explain a bigger percentage of cases, contributing to the knowledge of the aHUS pathophysiology.

There is no consensus so far on the duration of eculizumab therapy. ${ }^{7,19-21}$ In the p years, lifelong treatment with eculizumab has been questioned, particularly in view of potential side effects and high costs. In studies performed to date, the risk of recurrence after withdrawal is around 35\%, being higher in the first 12 months after suspension. ${ }^{19}$ On the contrary, patients without a pathogenic mutation identified, like our patient, were associated with a low risk of disease recurrence. In this particular case of aHUS appearance in the neonatal period, experts recommend that the duration of therapy should not be less than 36 months. ${ }^{20,22}$

After withdrawal, follow-up must be systematic and careful as rapid restarting of eculizumab treatment may allow aHUS remission and full renal recovery. ${ }^{19,20}$

\section{Conclusion}

Diagnosis of neonatal aHUS can be challenging because of disease rarity, phenotypic heterogeneity, and potential overlap with other manifestations that may confound it, such as perinatal asphyxia or sepsis/disseminated intravascular coagulation. Patient's clinical characteristics, laboratorial tests, and clinical evolution will help achieve an accurate diagnosis.

Eculizumab made a great improvement in the aHUS patient's quality of life and morbidity. Nevertheless, there are still some debatable issues especially in neonates on when to start therapy, what dose to use, and how to monitor treatment and the timing of withdrawal.

aHUS is a disease that needs further prospective research to provide updated guidelines for an even more accurate management.

\section{Conflict of Interest}

None declared.

\section{References}

1 Walsh PR, Johnson S. Treatment and management of children with haemolytic uraemic syndrome. Arch Dis Child 2018;103(03): 285-291

2 Azevedo A, Faria B, Teixeira C, et al. Portuguese consensus document statement in diagnostic and management of atypical hemolytic uremic syndrome. Port J Nephrol Hypert 2018;32(03):1-22

3 Dixon BP, Gruppo RA. Atypical hemolytic uremic syndrome. Pediatr Clin North Am 2018;65(03):509-525

4 Anastaze Stelle K, Gonzalez E, Wilhelm-Bals A, Michelet PR, Korff $\mathrm{CM}$, Parvex P. Efficacité du traitement d'un syndrome hémolytique et urémique atypique néonatal par anticorps monoclonal C5. Arch Pediatr 2016;23(03):283-286
5 Çakar N, Ozcakar ZB, Ozaltin F, et al. Atypical hemolytic uremic syndrome in children aged $<2$ years. Nephron 2018;139(03): 211-218

6 Greenbaum LA, Fila M, Ardissino G, et al. Eculizumab is a safe and effective treatment in pediatric patients with atypical hemolytic uremic syndrome. Kidney Int 2016;89(03):701-711

7 Loirat C, Fakhouri F, Ariceta G, et al; HUS International. An international consensus approach to the management of atypical hemolytic uremic syndrome in children. Pediatr Nephrol 2016;31 (01):15-39

8 Michaux K, Bacchetta J, Javouhey E, Cochat P, Frémaux-Bacchi V, Sellier-Leclerc AL. Eculizumab in neonatal hemolytic uremic syndrome with homozygous factor $\mathrm{H}$ deficiency. Pediatr Nephrol 2014;29(12):2415-2419

9 Szarvas N, Szilágyi Á, Tasic V, et al. First-line therapy in atypical hemolytic uremic syndrome: consideration on infants with a poor prognosis. Ital J Pediatr 2014;40:101

10 Alonso-Triana YM, Perrino MJ. Eculizumab for atypical hemolytic uremic syndrome in newborn: a case report [in Spanish]. Farm Hosp 2015;39(04):217-218

11 Ariceta G, Arrizabalaga B, Aguirre M, Morteruel E, Lopez-Trascasa M. Eculizumab in the treatment of atypical hemolytic uremic syndrome in infants. Am J Kidney Dis 2012;59(05):707-710

12 Biran V, Fau S, Jamal T, et al. Perinatal asphyxia may present with features of neonatal atypical hemolytic uremic syndrome. Pediatr Nephrol 2007;22(12):2129-2132

13 Fallahpour M, Hafizi A, Fouladgar A, Rajabian B. Neonatal atypical hemolytic uremic syndrome may cause prenatal asphyxia. Arch Iran Med 2012;15(11):729-730

14 Sharma S, Pradhan M, Meyers KEC, Le Palma K, Laskin BL. Neonatal atypical hemolytic uremic syndrome from a factor $\mathrm{H}$ mutation treated with eculizumab. Clin Nephrol 2015;84(03): 181-185

15 Besbas N, Gulhan B, Karpman D, et al. Neonatal onset atypical hemolytic uremic syndrome successfully treated with eculizumab. Pediatr Nephrol 2013;28(01):155-158

16 Ito $\mathrm{S}$, Hidaka $\mathrm{Y}$, Inoue $\mathrm{N}$, et al. Safety and effectiveness of eculizumab for pediatric patients with atypical hemolytic-uremic syndrome in Japan: interim analysis of post-marketing surveillance. Clin Exp Nephrol 2019;23(01):112-121

17 Lebel E, Trahtemberg U, Block C, Zelig O, Elinav H. Post-eculizumab meningococcaemia in vaccinated patients. Clin Microbiol Infect 2018;24(01):89-90

18 Tiwari L, Vashissht N, Kaur P, Gupta N, Saikia B, Puliyel J. 568 Neonatal hemolytic uremic syndrome. Arch Dis Child 2012; 97(Suppl 2):A1-A539

19 Wijnsma KL, Duineveld C, Wetzels JFM, van de Kar NCAJ. Eculizumab in atypical hemolytic uremic syndrome: strategies toward restrictive use. Pediatr Nephrol 2019;34(11):2261-2277

20 Ariceta G. Optimal duration of treatment with eculizumab in atypical hemolytic uremic syndrome (aHUS)-a question to be addressed in a scientific way. Pediatr Nephrol 2019;34(05): 943-949

21 Fakhouri F, Loirat C. Anticomplement treatment in atypical and typical hemolytic uremic syndrome. Semin Hematol 2018;55 (03):150-158

22 Goodship TH, Cook HT, Fakhouri F, et al; Conference Participants. Atypical hemolytic uremic syndrome and C3 glomerulopathy: conclusions from a "Kidney Disease: Improving Global Outcomes" (KDIGO) Controversies Conference. Kidney Int 2017;91(03): $539-551$ 